\title{
Performance-based intersection layout under a flyover for heterogeneous traffic
}

\author{
Avijit Maji • Akhilesh Kumar Maurya • \\ Suresh Nama $\cdot$ Prasanta K. Sahu
}

Received: 4 February 2015/Revised: 27 March 2015/Accepted: 15 April 2015/Published online: 26 May 2015

(C) The Author(s) 2015. This article is published with open access at Springerlink.com

\begin{abstract}
Flyovers are constructed to manage heavy through movement. However, traffic operations underneath a flyover remain unmanaged and often pose a major concern in developing countries with non-lane-based heterogeneous traffic. This may reduce the overall benefit of a flyover. An alternative intersection layout is proposed to improve traffic operations at the intersection underneath a flyover. The proposed layout segregates the traffic movements through effective channelization. A traffic island is also proposed in the middle of the intersection to facilitate concurrent right-turning movements. This layout helps in eliminating a signal phase and cuts down traffic cycle time by $40 \%$. A microsimulation-based traffic simulation model is developed for the evaluation of the proposed layout. The simulation model demonstrates effectiveness of the proposed layout. Average delay and average queue length are compared to measure the effectiveness. Traffic volume sensitivity analysis is conducted to estimate the capacity of the proposed layout. An intersection underneath a flyover along the Eastern Expressway in Mumbai is considered for the case study. The effectiveness of the
\end{abstract}

A. Maji $(\bowtie)$

Indian Institute of Technology Bombay, Mumbai, India

e-mail: avijit.maji@gmail.com

\author{
A. K. Maurya $\cdot$ S. Nama \\ Indian Institute of Technology Guwahati, Guwahati, India \\ e-mail: maurya@iitg.ernet.in \\ S. Nama \\ e-mail: nsureshce@gmail.com \\ P. K. Sahu \\ Post Doctoral Fellow, University of Regina, \\ Regina, SK S4S 0A2, Canada \\ e-mail: prasantsahu222@gmail.com
}

proposed layout at the study location for varying flow level is evaluated by comparing average delay, average stop delay, average number of stops per vehicle, average queue length, and maximum queue length.

Keywords Intersection layout - Channelization - Traffic operational performance - Flyover intersection .

Heterogeneous traffic

\section{Introduction}

At an intersection, separating the grade and allowing the heavy traffic-movement to flow uninterrupted can mitigate congestion. Flyover is one such grade separation, where the through traffic-movement is bridged over an intersection. The 1965 Blue Book [1] provided the design criteria of two-lane highway overpass or flyover. This type of gradeseparated configuration is suitable where adjacent properties are fully developed or right-of-way is constrained by sensitive land parcels. Overall benefit of a flyover depends on the volume of traffic diverted from the 'at-grade' intersection to the flyover. Previous studies for homogeneous traffic with lane discipline have concluded that capacity of an intersection can increase up to $300 \%$ when flyovers are constructed for heavy through movements along an arterial [2]. However, this increase relies on the traffic operation efficiency of the signalized intersection underneath the flyover. The through traffic using the flyover experiences no delay and the 'reduced at-grade traffic' improves the operational quality at the signalized intersection. In general, flyover helps in reducing vehicle delay at the intersection.

In India, the space underneath a flyover is not usually designed to facilitate simultaneous right-turning vehicular 
movements. However, developed countries use diamond interchange, single-point urban interchange, etc., for allowing such movements. These alternatives may not be feasible as flyovers in India are constructed in urban setup with limited right-of-way. Further, necessary detailed geometric design guidelines for heterogeneous traffic compositions with weak lane discipline (Indian traffic) are not available. In these situations, alternative intersection layouts that can efficiently manage Indian traffic have not been studied yet. Therefore, the purpose of this study is to develop an alternative intersection layout underneath a flyover that improves traffic operations. A microsimulation-based performance analysis of the proposed layout has been carried out for a real world case. In addition, a sensitivity analysis with seven different traffic flow levels is conducted to measure the performances (average queue length, maximum queue length, average delay, average stop time, and number of stops per vehicle) of the proposed layout.

\section{Literature review}

The performance measures to evaluate effectiveness, also known as measure of effectiveness (MOE), of an intersection layout generally are travel time, delay, queue length, capacity, safety, etc. [3, 4]. Although, numerous models are available to evaluate the MOEs of an intersection layout for homogeneous traffic; very few are available for heterogeneous traffic compositions. Wang et al. [5] developed a conflict-point detection model based on microsimulation of heterogeneous traffic (i.e., motorized and non-motorized vehicles) in China. This model is used to identify the conflict-points of existing and proposed improvements of an intersection, which is the surrogate measure of intersection safety. Similarly, Lu et al. [6] considered the conflict-points at an un-signalized intersection to determine the level of safety for heterogeneous traffic compositions. This model is dependent on site characteristics, such as geometrics, traffic conditions, roadway, environmental conditions, etc. In another study, Abdel-Arty et al. [7] developed an influence-area-based model to evaluate intersection safety for homogeneous traffic. The same model can be used to analyze heterogeneous traffic flow at an intersection with the concept of "varied influence areas" [8].

Unconventional intersection layouts help in reducing intersection delay and travel time by managing the critical conflicting movements in a way that they no longer remain critical. Researchers have extensively studied crossover displaced left-turn [9-12, 13] and other unconventional intersections and interchanges [14-16]. However, these studies are limited to developed countries where homogeneous traffic and strong lane discipline prevail. On the other hand, studies focusing on unconventional intersection design for heterogeneous traffic are rare. Vedagiri and Daydar [17] assessed suitability of continuous flow intersection for Indian traffic by adopting a standard intersection layout mainly developed for homogeneous traffic. Similarly, Maji and Bhattacharya [18] presented the concept of developing innovative intersections for the Indian scenario but the performance of heterogeneous traffic in the innovative intersection layouts is not discussed. Other researches related to heterogeneous traffic mainly focus on traffic flow modeling [19], measuring influences of traffic operational elements [20], calibration of non-lanebased heterogeneous traffic [21], etc. Therefore, comprehensive research is required in intersection geometric design and traffic operations for Indian conditions.

\section{Existing layout and traffic operations}

Highway agencies in India and other developing nations consider flyovers to alleviate recurring congestion at intersections. Countries like USA, France, Germany, etc., had considered flyovers or overpass as one of the mitigation plans for congested arterials way back in the 1950s and 1960s [2]. However, with increase in operating speed and traffic volume this layout has become obsolete for highspeed corridors in those countries. Studies have shown that adjacent signalized intersections along the corridor discount the benefits anticipated from a flyover [2]. Generally, the posted speed limit in major arterials and expressways in India varies from 80 to $120 \mathrm{kmph}$ [22-24]. Moreover, traffic in low and medium income nations comprises both low-speed and high-speed vehicles with varying sizes. It is the heterogeneity in traffic composition that keeps the operating speed low. In these countries, highway corridor improvement plans are implemented in phases subjected to availability of funds. Often, it takes decades to allocate funds for adjacent intersections after a flyover is constructed at a location. In these situations, constructing flyovers over one intersection at a time provides temporary and localized relief that extends over the corridor with construction of subsequent flyovers.

The size of the intersection underneath a flyover depends on the width of the cross road or minor road. Most arterials in Indian metropolitan cities are median-divided highways with three to four lanes in each direction. The arterials are generally constructed as closed section highways with a sidewalk of approximate width $2 \mathrm{~m}$ on either side, while, the median width varies from 2 to $4 \mathrm{~m}$ with no turn lane pockets at the intersection. Overall, the width of the right-of-way varies from 30 to $50 \mathrm{~m}$. Hence, the size of an intersection for two intersecting arterials with six-lane 
flyover along a major arterial varies from $30 \times 50 \mathrm{~m}$ to $50 \times 60 \mathrm{~m}$. On the other hand, an intersection has a smaller footprint when the cross road is of lower category and the number of lanes on the flyover is two in each direction. Overall length of a flyover can vary from 350 to $750 \mathrm{~m}$. A typical layout of an intersection underneath a flyover is shown in Fig. 1.

Flyovers are used for uninterrupted through movements along its direction. All turn-movements and through movements along the cross road is managed at the intersections underneath it. Hence, depending on the traffic volume exiting or entering the arterial with flyover, a two to four-lane ramp is used to connect the arterial with the intersection. The major movements from the exit ramp are left-turn and right-turn at the intersection. Very few vehicles mostly transit buses may travel straight through the ramp crossing the intersection to pick up and drop off passengers who need transfer at the intersection. Vehicles from the cross road can go through, turn left or turn right at the intersection. In India and other low and medium income nations, there are wide varieties of vehicles, such as two-wheelers, three-wheelers, mini-truck, medium sized truck, passenger cars, mini-bus, regular sized bus, etc., using the highway facility. Each of these vehicles occupies a different area and has distinct operating characteristics. The approach to the intersection may have marked lanes; however, vehicles seldom follow lane marking while stopping in red traffic light. They try to squeeze in wherever space is available. The two-wheeler riders zip through the stopped four-wheelers and join front of the queue. When the signal turns green, the two-wheelers dissipate first followed by other vehicles.

An intersection underneath a flyover is generally signalized when the cross road is an arterial or carries heavy traffic volume. For low volume and less important cross roads, it remains un-signalized. If signalized, all movements are controlled by split phases (i.e., there is one phase for each direction), leading to a total of four phases. The left-turn movements (considering left-hand driving rules in
India) usually have overlapping phases. A typical phase diagram is shown in Fig. 2. Heavy turning volume is expected at these locations and hence, concurrent right-turn or through movements are not allowed. Traffic-actuated signals are not common in India. Therefore, these signals operate at fixed-time cycle. During daytime, traffic enforcement officers can manually adjust the splits by observing the queue formed. Generally, the cycle length of these signals varies from 150 to $200 \mathrm{~s}$.

\section{Proposed layout}

In the proposed layout, the turn-movements are segregated with positive guidance. This enables concurrent movement of opposing right-turning traffic. All right-turn movements are channelized by providing a channelization island (refer to Fig. 3). The island is considered on the crossroad to split the right-turn movements from the combined through and left-turn movements. This island should be extended to hold the peak hour right-turn queue. Depending on the traffic volume, the width of right-turn bay and the through lane could be between 3.5 and $10.5 \mathrm{~m}$. A pork chop island may be considered near the intersection to channelize the left-turn movement from through movement (see Fig. 3 for details). Channelization island is considered on the ramp approaching the intersection to separate the right-turn movements from the left-turn movements. Again, the length of this channelization island depends on the queue length. The width of left-turn bay could be between 3.5 and

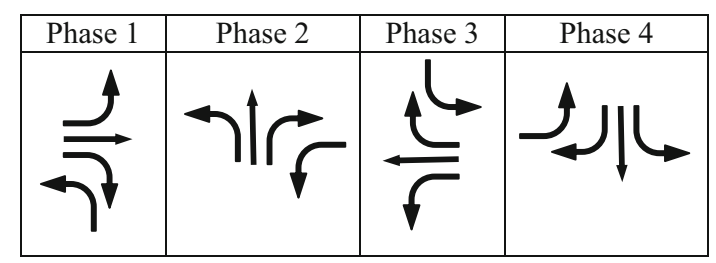

Fig. 2 Typical signal phasing for intersections underneath a flyover

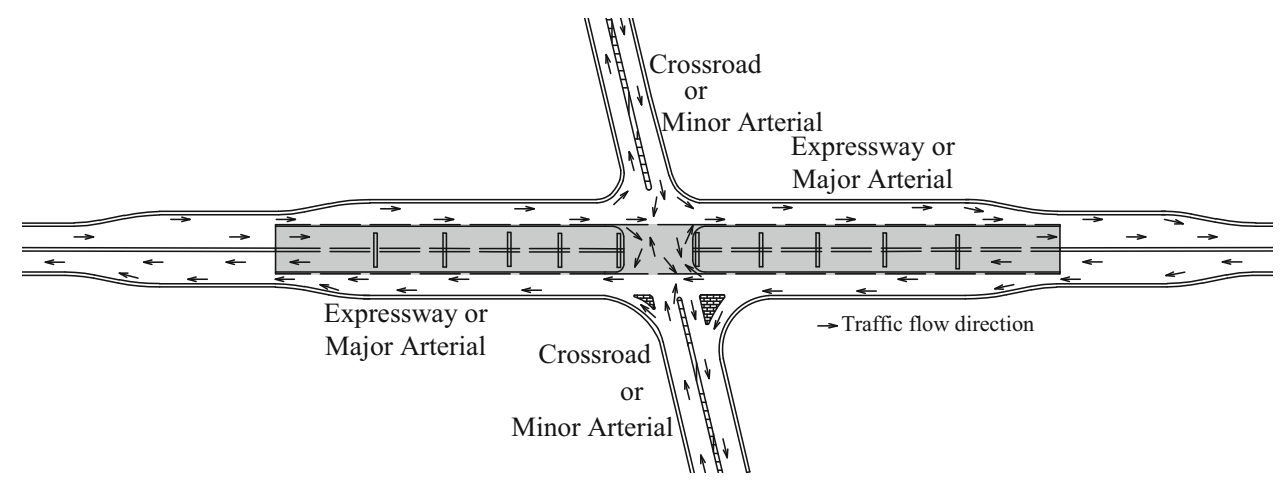

Fig. 1 Typical layout of intersection underneath a flyover 


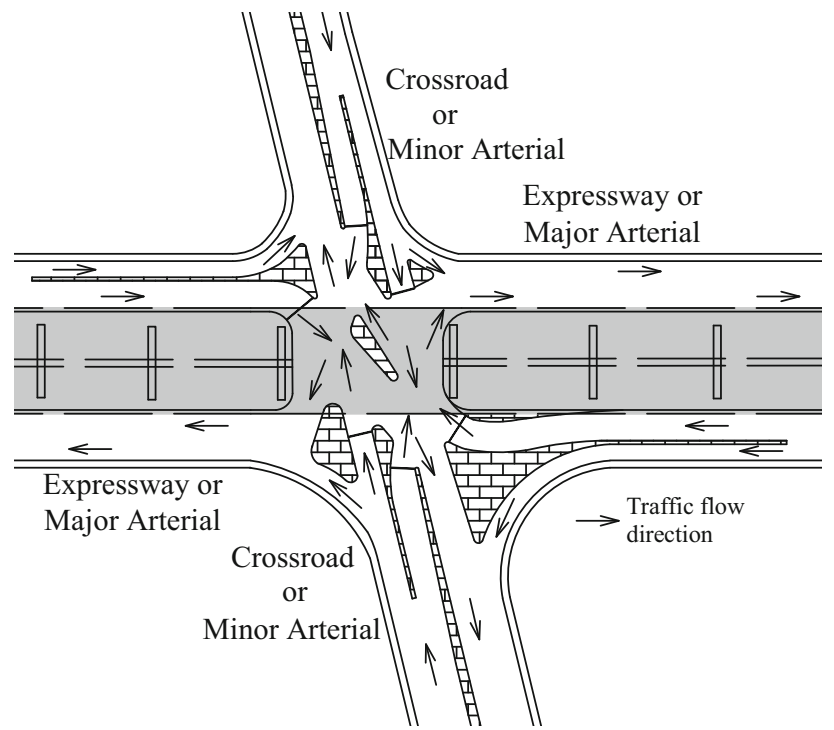

Fig. 3 Proposed intersection layout

$7.0 \mathrm{~m}$ and right-turn bay between 7.0 and $10.5 \mathrm{~m}$; whereas, the channelization islands are designed conforming to IRC: SP 41-1994 [25] or AASHTO [26]. Here, the through movement along the ramp is diverted to the left, which eventually makes a U-turn on the crossroad followed by a left-turn to get back on the ramp. The location of U-turn on the cross road is critical and it is expected to be within a distance of $100-500 \mathrm{~m}$ from the main intersection and beyond the influence zone of the queue formed in the cross road. Though the distance traveled would increase by 200-1,000 m, the overall delay of the transit bus might decrease compared to the existing configuration. The U-turn location on cross road may be operated by a synchronized two-phase signal. Great care should be taken in deciding the width of the channelization. Considering the driving behavior in India, providing a too narrow or too wide width may impact the total throughput through the channelized portion. It is recommended that a field study be conducted in estimating the optimum width of channelization for heterogeneous traffic with weak lane discipline.

One of the critical components of the layout is the center island. This is a pork chop island, which provides physical separation between concurrent movements of the opposing right-turning traffic from the cross road and the ramp. This island is similar to the traffic island provided in the center portion of a single point urban interchange and should be designed considering the design vehicle swept path. A painted island could be adequate for a single point urban interchange serving homogeneous traffic; however, for heterogeneous traffic with weak lane discipline, a raised traffic island is suggested. In the proposed layout, the concept of "least control is the best control" for traffic management is not followed because heterogeneous traffic with weak lane discipline requires additional guidance and control to enhance traffic safety.

The total number of signal phases can be reduced to three with the concurrent right-turn movements. Similar to existing traffic operations, the left-turn movements can still overlap with the corresponding right-turn movements. Also, a left-turn on red (similar to right-turn on red for right-hand driving rules) is allowed here. A detailed phase diagram of the proposed layout is shown in Fig. 4. The left-turning traffic from the cross road is served by two exclusive phases (Phases 1 and 3), while, the left-turning traffic from the ramp is served by only one exclusive phase (Phase 2). Hence, high left-turning traffic volume from the ramp may influence the Phase 2 split and signal cycle length.

\section{Analysis of proposed layout using microsimulation software VISSIM}

The proposed layout is analyzed using microsimulation software VISSIM. Simulation of the heterogeneous traffic with weak lane discipline requires special procedure in modeling to address the unique characteristics of such traffic. Normally, in VISSIM the available vehicle models are of standard types, such as car, bus, motorcycles, and truck. However, in heterogeneous traffic conditions there exists tractors, motorized and non-motorized three-wheelers, etc. Therefore, in the VISSIM simulation, the static and dynamic characteristics of every vehicle type in terms of length, width, acceleration, deceleration, and speed ranges should be defined accurately. In the current simulation, the vehicle types considered are car, two-wheeler, three-wheeler, light commercial vehicle (LCV), bicycle, bus, and truck. Further, to simulate the non-lane behavior or weak lane discipline, certain provisions in VISSIM are explored. For example, the total road width is defined as a single lane of equivalent road width (say $10.5-\mathrm{m}$ wide lane to simulate a 3 lane roadway). The desired position of a vehicle at free flow condition could be any position in the entire roadway width. Hence, "Observe vehicles on next lane(s)" and "Diamond-shaped queuing" options are checked in the simulation software. Moreover, overtaking on the same lane is allowed from both sides-left and right.

To determine the need for calibration, the model is simulated with the predefined setting and various traffic stream parameters values are obtained. These parameters values are then compared with field values. If the error is insignificant, the model can run with default settings. Otherwise, the calibration steps must be followed [27, 28]. As per multiparameter sensitivity analysis conducted on heterogeneous traffic in [28], the desired speed distribution and minimum gap were found as sensitive parameters. In the present study, various VISSIM parameters are calibrated based on the values suggested in different 


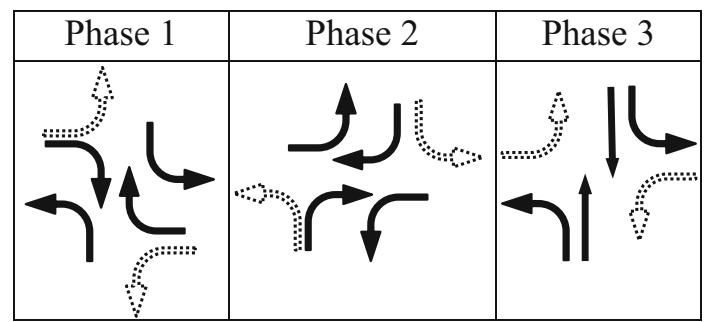

Fig. 4 Signal phasing for the proposed layout studies [27-29]. Validation is carried out using the field data (queue length and delay) to confirm the prediction capability of the calibrated model.

\section{Case study}

An intersection with flyover on Eastern Expressway at Airoli-Mulund Link Road in Mumbai, India is considered for the real world case study. Its layout is similar to Fig. 1.

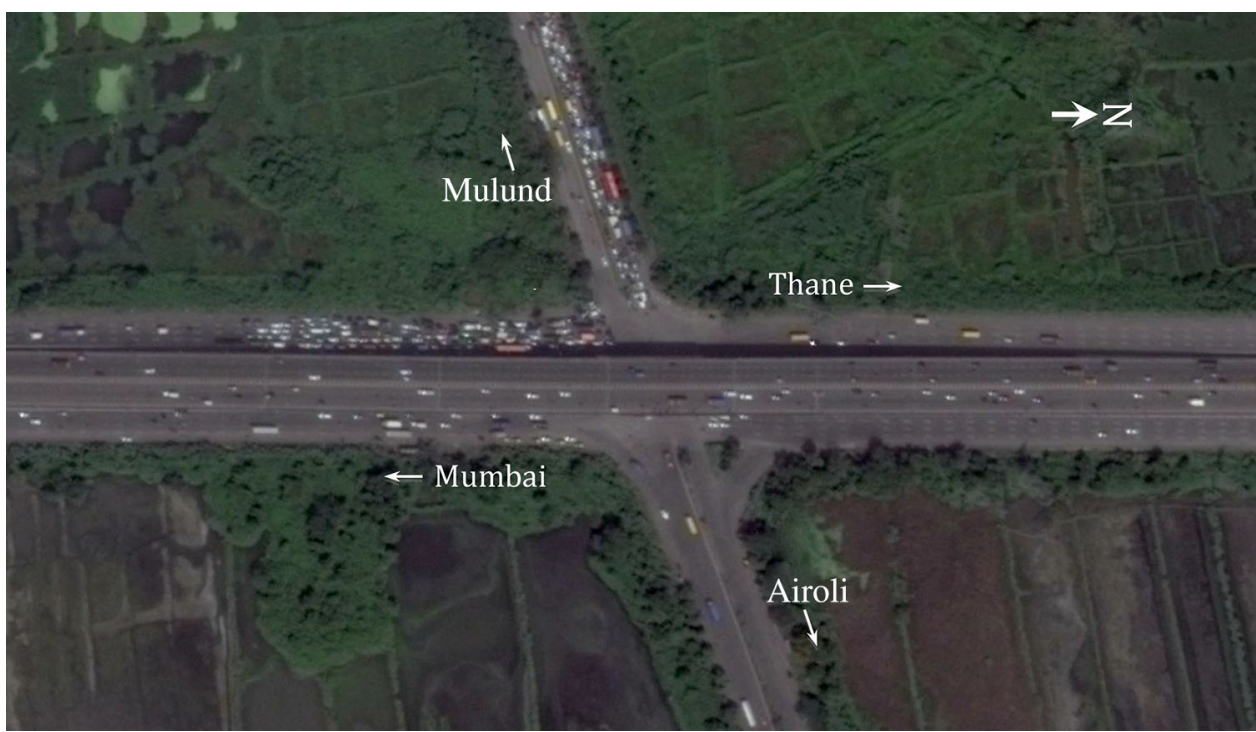

Fig. 5 Satellite image of Eastern Expressway and Airoli-Mulund link road intersection in Mumbai, India (satellite image from Google earth)

Table 1 Turning movement count at existing intersection between 17:00 and 19:00

\begin{tabular}{|c|c|c|c|c|c|c|c|c|c|c|c|}
\hline $\begin{array}{l}\text { Intersection } \\
\text { from }\end{array}$ & $\begin{array}{l}\text { Approach } \\
\text { to }\end{array}$ & $\begin{array}{l}\text { Two- } \\
\text { wheeler }\end{array}$ & $\begin{array}{l}\text { Three- } \\
\text { wheeler }\end{array}$ & Car & $\begin{array}{l}\text { Mini- } \\
\text { bus }\end{array}$ & $\begin{array}{l}\text { Full } \\
\text { bus }\end{array}$ & LCV & $\begin{array}{l}\text { Dual- } \\
\text { axle }\end{array}$ & $\begin{array}{l}\text { Multi- } \\
\text { axle }\end{array}$ & Bicycle & $\begin{array}{l}\text { Total } \\
\text { vehicles }\end{array}$ \\
\hline \multirow[t]{4}{*}{ Airoli } & Left & 484 & 72 & 1,062 & 8 & 62 & 70 & 68 & 16 & 0 & 1,842 \\
\hline & Through & 533 & 98 & 579 & 3 & 52 & 44 & 34 & 14 & 1 & 1,358 \\
\hline & Right & 546 & 57 & 595 & 6 & 53 & 13 & 14 & 16 & 0 & 1,300 \\
\hline & Grand total & 1,563 & 227 & 2,236 & 17 & 167 & 127 & 116 & 46 & 1 & 4,500 \\
\hline \multirow[t]{4}{*}{ Mumbai } & Left & 139 & 72 & 571 & 0 & 4 & 73 & 52 & 27 & 0 & 938 \\
\hline & Through & 46 & 38 & 62 & 3 & 45 & 6 & 1 & 1 & 3 & 205 \\
\hline & Right & 842 & 107 & 1,172 & 11 & 67 & 62 & 125 & 31 & 0 & 2,417 \\
\hline & Grand total & 1,027 & 217 & 1,805 & 14 & 116 & 141 & 178 & 59 & 3 & 3,560 \\
\hline \multirow[t]{4}{*}{ Mulund } & Left & 286 & 107 & 335 & 2 & 6 & 22 & 41 & 9 & 1 & 809 \\
\hline & Through & 416 & 105 & 332 & 1 & 39 & 44 & 29 & 9 & 0 & 975 \\
\hline & Right & 320 & 122 & 665 & 0 & 20 & 99 & 73 & 17 & 0 & 1,316 \\
\hline & Grand total & 1,022 & 334 & 1,332 & 3 & 65 & 165 & 143 & 35 & 1 & 3,100 \\
\hline \multirow[t]{4}{*}{ Thane } & Left & 137 & 33 & 198 & 0 & 19 & 6 & 11 & 8 & 4 & 416 \\
\hline & Through & 32 & 50 & 48 & 1 & 23 & 5 & 4 & 0 & 0 & 163 \\
\hline & Right & 319 & 149 & 261 & 1 & 1 & 32 & 57 & 21 & 0 & 841 \\
\hline & Grand total & 488 & 232 & 507 & 2 & 43 & 43 & 72 & 29 & 4 & 1,420 \\
\hline
\end{tabular}


The Eastern Expressway connects the central business district of Mumbai (about $20 \mathrm{~km}$ south of the intersection) with the northern suburb of Thane (about $10 \mathrm{~km}$ north of the intersection). The cross road is a major arterial that connects Airoli in Navi Mumbai (about $6 \mathrm{~km}$ east of the intersection) and Mulund in Mumbai (about $3 \mathrm{~km}$ west of the intersection). A satellite image of the intersection is shown in Fig. 5. At this location, the Eastern Expressway is a median-divided highway with five lanes in each direction. The total length of this flyover is about $750 \mathrm{~m}$ and the size of the intersection under the flyover is approximately
$30 \times 60 \mathrm{~m}$. The flyover accommodates three of the five through lanes in each direction and the two exit-lanes are widened to four-lane approach at the signalized intersection. Similarly, beyond the intersection, four-lanes are reduced to two lanes before joining the three through lanes from the flyover. On the other hand, the Airoli-Mulund Link Road is a six-lane (three lanes in each direction) divided highway with $2-\mathrm{m}$ wide median. On the east side of the intersection, the left-turn movements from the expressway to the link road and from the link road to the expressway are channelized by pork chop islands. The

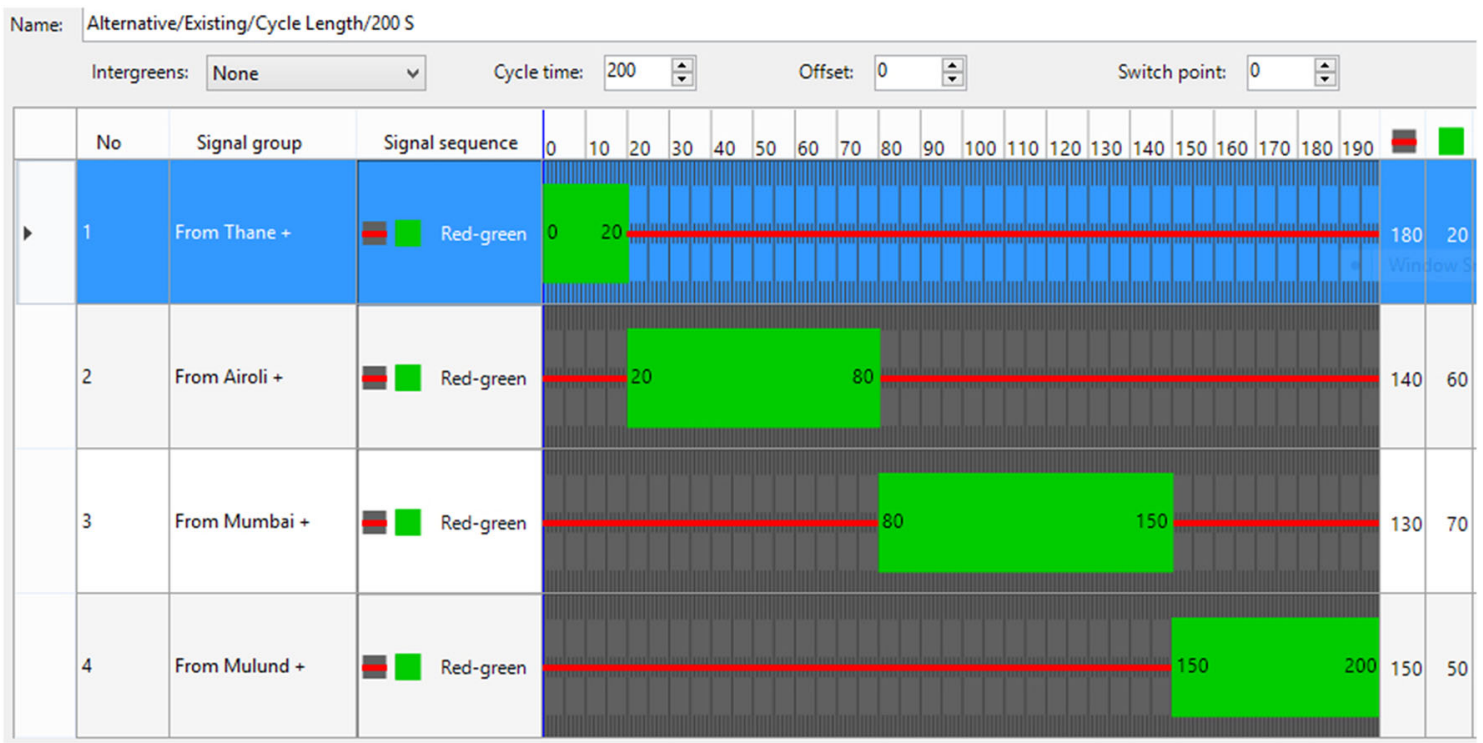

(a)

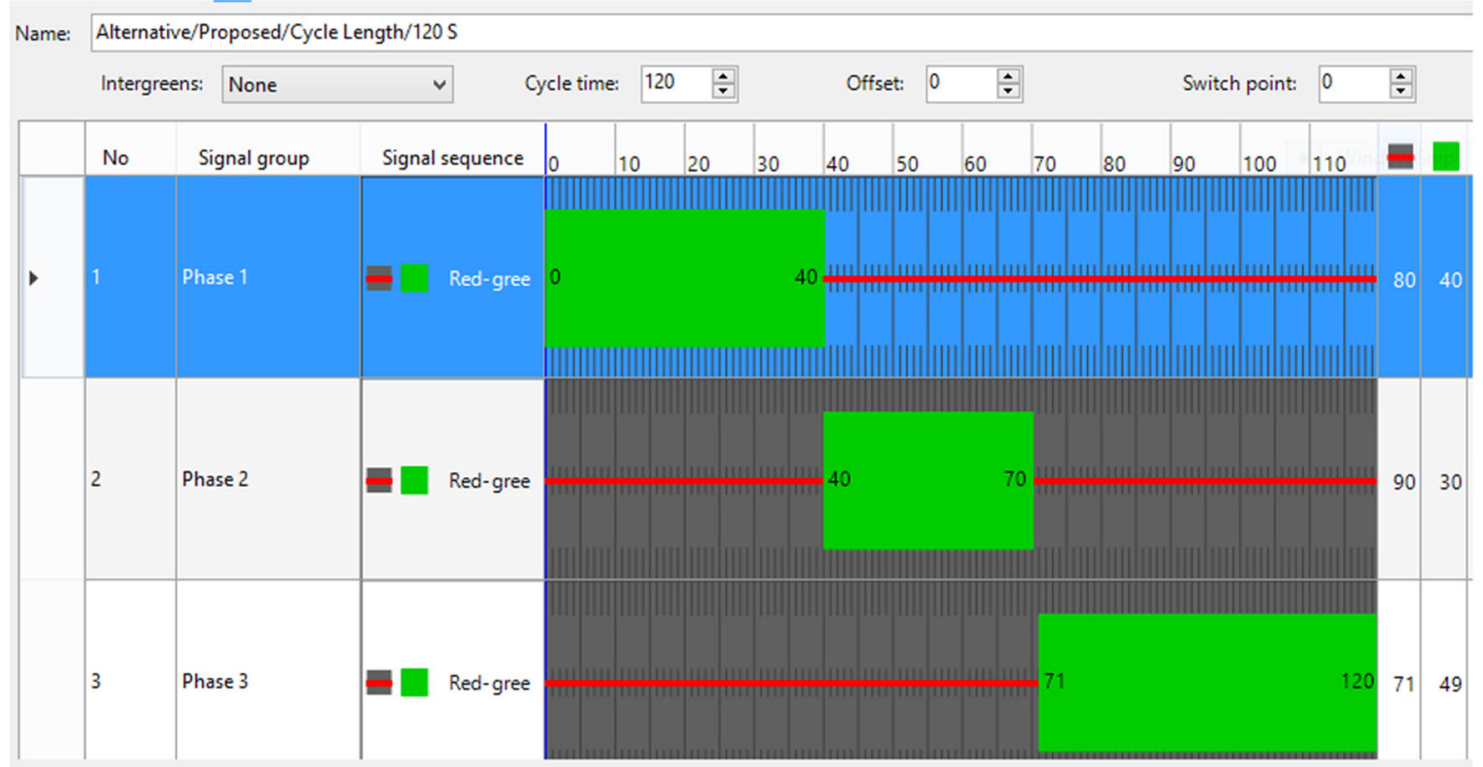

(b)

Fig. 6 Sample snapshot of signal time allocation in VISSIM. a Existing layout with $200 \mathrm{~s}$ cycle length. b Proposed layout with $120 \mathrm{~s}$ cycle length. c Proposed layout with 200 s cycle length 


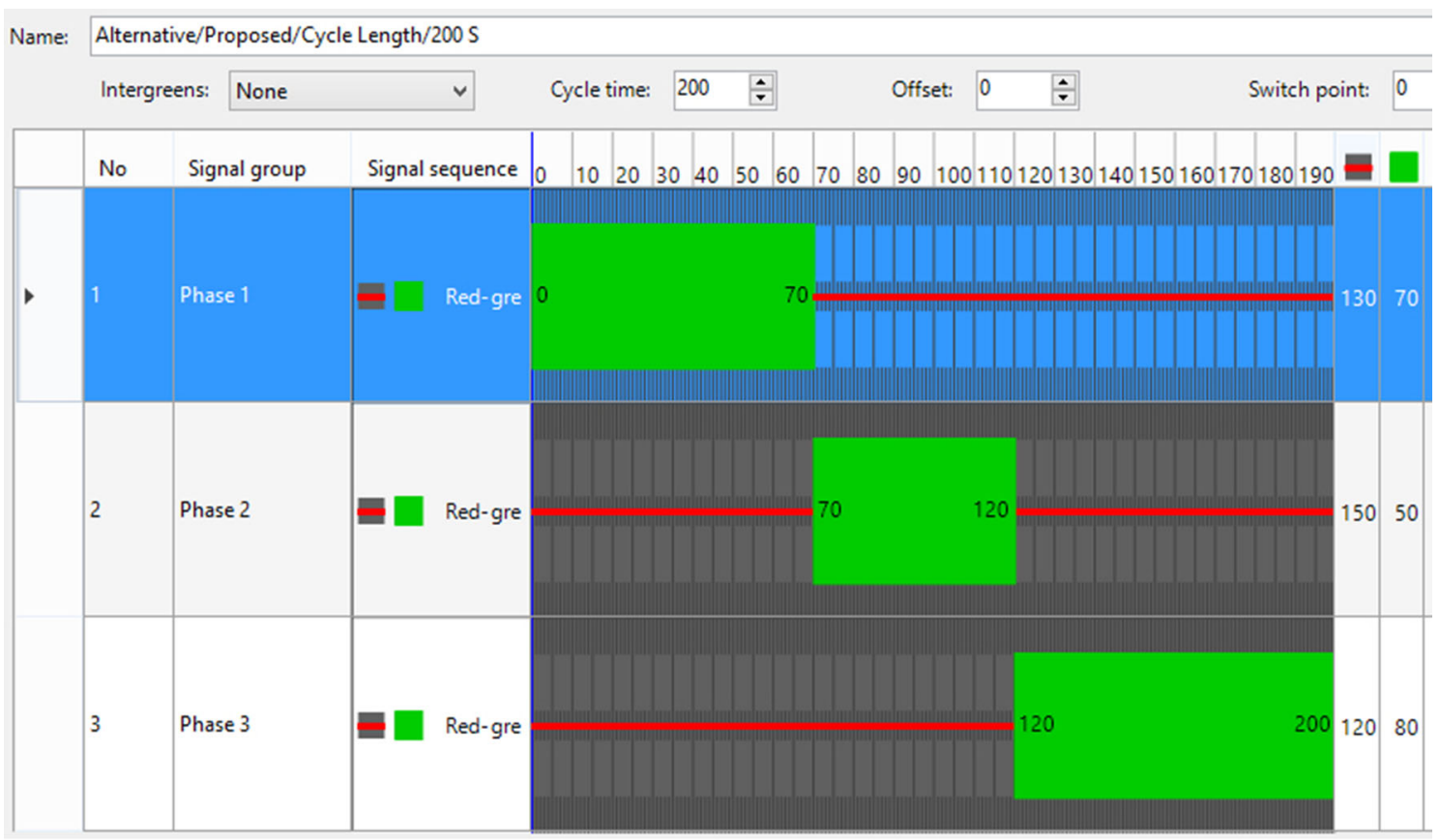

(c)

Fig. 6 continued

proposed layout as shown in Fig. 3 is studied for this location.

\subsection{Traffic and simulation data}

This intersection is signalized and operates at a fixed cycle length of $200 \mathrm{~s}$. The phasing scheme is similar to Fig. 2. The queue length at the intersection along the flyover usually remains within $200 \mathrm{~m}$. Sometimes, on rare occasions, it extends beyond $300 \mathrm{~m}$ and impacts the through movements on the expressway. During morning peak hours, the heavy traffic movements are in the direction of the central business district of Mumbai (i.e., south of the intersection) and the reverse trend prevails during afternoon peak hours. Hence, the westbound left-turn movements and eastbound right-turn movements are heavy during morning peak hours. On the other hand, the northbound right-turn and left-turn movements are heavy during afternoon peak hours. The heavy movements during morning peak hours are served by two different phases, but in the afternoon, heavy movements are served by one phase. Moreover, any impact to the northbound right-turn and left-turn movements can affect the through movement on the expressway. Therefore, the period of afternoon peak hours is considered as critical in evaluating the proposed layout.

Traffic data were collected during evening peak period (17:00-19:00) on March 28th, 2014, which was a sunny day. The detailed turning movement counts is given in
Table 1. A microsimulation-based model for existing and proposed layouts was developed using VISSIM. The existing layout was calibrated and validated for field condition with signal cycle length of $200 \mathrm{~s}$. However, the existing and the proposed layouts were evaluated and compared for cycle length of $80,120,150$, and $200 \mathrm{~s}$. A sample of the phasing scheme implemented in the simulation models is shown in Fig. 6. Both the existing and proposed layouts were evaluated for various MOE parameters discussed earlier.

\section{Results}

The calibrated and validated simulation model (see Sect. 5) of the existing layout was further used to develop the simulation model for the proposed layout at the case study location. Both models were simulated for five different seed values at various cycle lengths $(80,120,150$, and $200 \mathrm{~s})$. The splits of the cycle lengths considered and the average intersection delay are reported in Table 2. It was observed that the minimum intersection delay for the existing layout was at $200 \mathrm{~s}$ cycle length; however, for the proposed layout it was at $80 \mathrm{~s}$ cycle length. At $80 \mathrm{~s}$ cycle length, one of the splits for the proposed layout could be as low as $20 \mathrm{~s}$. Considering the Indian traffic conditions and driver behavior, $20 \mathrm{~s}$ split might be practically inadequate to satisfy driver expectancy at this intersection. Hence, $120 \mathrm{~s}$ was considered as an optimum cycle length for the 
Table 2 Cycle and phase lengths considered and corresponding intersection delay

\begin{tabular}{|c|c|c|c|c|c|c|}
\hline Alternatives & Cycle length (s) & Phase $1(\mathrm{~s})$ & Phase $2(\mathrm{~s})$ & Phase $3(\mathrm{~s})$ & Phase 4 (s) & Average intersection delay (s) \\
\hline \multirow[t]{4}{*}{ Existing } & 80 & 25 & 25 & 10 & 20 & 118 \\
\hline & 120 & 35 & 35 & 20 & 30 & 75 \\
\hline & 150 & 40 & 50 & 20 & 40 & 72 \\
\hline & 200 & 70 & 60 & 20 & 50 & 56 \\
\hline \multirow[t]{4}{*}{ Proposed } & 80 & 25 & 20 & 35 & - & 16 \\
\hline & 120 & 40 & 30 & 50 & - & 18 \\
\hline & 150 & 50 & 40 & 60 & - & 29 \\
\hline & 200 & 70 & 50 & 80 & - & 36 \\
\hline
\end{tabular}

Table 3 Average delay and average queue length of existing and proposed layouts

\begin{tabular}{|c|c|c|c|c|c|c|c|}
\hline \multirow{2}{*}{\multicolumn{2}{|c|}{ Intersection approach }} & \multirow{2}{*}{\multicolumn{2}{|c|}{$\frac{\text { Existing layout }}{200 \mathrm{~s} \text { cycle length }}$}} & \multicolumn{4}{|c|}{ Proposed layout } \\
\hline & & & & \multicolumn{2}{|c|}{120 s cycle length } & \multicolumn{2}{|c|}{200 s cycle length } \\
\hline From & To & $\mathrm{AD}(\mathrm{s})$ & $\mathrm{AQL}(\mathrm{m})$ & $\mathrm{AD}(\mathrm{s})$ & AQL (m) & $\mathrm{AD}(\mathrm{s})$ & $\mathrm{AQL}(\mathrm{m})$ \\
\hline Thane & Right and left & 102 & 29 & 11 & $8^{\mathrm{a}}$ & 17 & $11^{\mathrm{a}}$ \\
\hline Thane & Through & 102 & 29 & $N A^{b}$ & $\mathrm{NA}^{\mathrm{b}}$ & $\mathrm{NA}^{\mathrm{b}}$ & $\mathrm{NA}^{\mathrm{b}}$ \\
\hline Airoli & Right & 121 & 177 & 24 & 23 & 81 & 36 \\
\hline Airoli & Through and left & 121 & 177 & 24 & $36^{\mathrm{a}}$ & 81 & $110^{\mathrm{a}}$ \\
\hline Mumbai & Right and left & 55 & 60 & 30 & $49^{\mathrm{a}}$ & 37 & $57^{\mathrm{a}}$ \\
\hline Mumbai & Through & 55 & 60 & $\mathrm{NA}^{\mathrm{b}}$ & $\mathrm{NA}^{\mathrm{b}}$ & $\mathrm{NA}^{\mathrm{b}}$ & $\mathrm{NA}^{\mathrm{b}}$ \\
\hline Mulund & Right & 100 & 104 & 26 & 24 & 71 & 46 \\
\hline Mulund & Through and left & 100 & 104 & 26 & $28^{\mathrm{a}}$ & 71 & 123 \\
\hline
\end{tabular}

$A D$ the average delay and $A Q L$ the average queue length

${ }^{a}$ Indicates left direction queue length as zero

${ }^{b}$ Indicates diversion of traffic from through direction to left as described in Sect. 4 (proposed layout)

proposed layout. The existing layout operating at $200 \mathrm{~s}$ cycle length was compared with the proposed layout operating at 120 and $200 \mathrm{~s}$ cycle lengths. The MOE parameters considered for comparison were average delay and average queue length. These two parameters showed significant improvements for the proposed layout at $120 \mathrm{~s}$ cycle length (Table 3 ). The average queue length was reduced by $60 \%-90 \%$; whereas, the average delay was reduced by $20 \%-90 \%$ with respect to the existing layout. These improvements indicate the efficiency of the proposed layout at the case study location.

Further, sensitivity analysis on performance of the proposed layout was conducted at $120 \mathrm{~s}$ cycle length by simulating the VISSIM model with varying traffic flow levels (provided in Table 4). First, the present flow level (i.e., flow level III in Table 4) was varied by step size of $33 \%$ to obtain flow level I ( $33 \%$ of the existing flow), flow level II (67\% of the existing flow), and flow level IV (133\% of the existing flow). The results at these flow levels demonstrated abrupt change in MOE parameters from flow level III to IV. Hence, additional three flow
Table 4 Flow levels chosen for the performance evaluation of the proposed layout

\begin{tabular}{lrrrrrrr}
\hline \multirow{2}{*}{$\begin{array}{l}\text { Intersection } \\
\text { approach }\end{array}$} & \multicolumn{6}{l}{ Flow level (veh/h) } \\
\cline { 2 - 8 } & I & \multicolumn{1}{l}{ II } & III & IV & IIIa & IIIb & IIIc \\
\hline Airoli & 750 & 1,500 & 2,250 & 3,000 & 2,500 & 2,625 & 2,750 \\
Mumbai & 600 & 1,200 & 1,800 & 2,375 & 2,000 & 2,100 & 2,175 \\
Mulund & 500 & 1,000 & 1,500 & 2,050 & 1,725 & 1,800 & 1,900 \\
Thane & 225 & 500 & 700 & 950 & 800 & 825 & 850 \\
Total flow & 2,075 & 4,200 & 6,250 & 8,375 & 7,025 & 7,350 & 7,675
\end{tabular}

levels (i.e., flow level IIIa, IIIb, and IIIc) with smaller step size were considered in between the flow levels III and IV for the sensitivity study.

The MOE parameters considered in the sensitivity study were average delay, maximum queue length, average queue length, average stop time, and number of stops per vehicle. The sensitivity study results are presented in Table 5. It was observed that all MOE parameters considered increases with an increase in traffic flow level. The 
Table 5 MOEs for performance evaluation of the proposed layout

\begin{tabular}{|c|c|c|c|c|c|c|c|c|c|}
\hline \multirow[t]{2}{*}{ MOE } & \multicolumn{2}{|l|}{ Approach } & \multicolumn{7}{|c|}{ Flow level } \\
\hline & From & To & I & II & III & VI & IIIa & IIIb & IIIc \\
\hline \multirow[t]{10}{*}{ Avg. queue length (m) } & Thane & Right & 4 & 7 & 8 & 9 & 8 & 9 & 9 \\
\hline & Thane & Left & 0 & 0 & 0 & 0 & 0 & 0 & 0 \\
\hline & Airoli & Right & 9 & 15 & 23 & 159 & 30 & 32 & 108 \\
\hline & Airoli & Through & 7 & 16 & 36 & 326 & 66 & 103 & 239 \\
\hline & Airoli & Left & 0 & 0 & 0 & 0 & 0 & 0 & 0 \\
\hline & Mumbai & Right & 12 & 28 & 49 & 72 & 32 & 36 & 44 \\
\hline & Mumbai & Left & 0 & 0 & 0 & 0 & 0 & 0 & 0 \\
\hline & Mulund & Right & 8 & 15 & 24 & 58 & 28 & 32 & 36 \\
\hline & Mulund & Through & 4 & 12 & 31 & 222 & 64 & 70 & 144 \\
\hline & Mulund & Left & 1 & 7 & 25 & 214 & 58 & 62 & 138 \\
\hline \multirow[t]{10}{*}{ Max queue length (m) } & Thane & Right & 22 & 24 & 32 & 40 & 36 & 33 & 34 \\
\hline & Thane & Left & 0 & 0 & 0 & 0 & 0 & 0 & 0 \\
\hline & Airoli & Right & 33 & 59 & 90 & 458 & 126 & 122 & 376 \\
\hline & Airoli & Through & 53 & 96 & 197 & 473 & 259 & 285 & 449 \\
\hline & Airoli & Left & 0 & 0 & 0 & 3 & 0 & 0 & 0 \\
\hline & Mumbai & Right & 62 & 94 & 168 & 224 & 137 & 158 & 185 \\
\hline & Mumbai & Left & 0 & 0 & 0 & 0 & 0 & 0 & 5 \\
\hline & Mulund & Right & 34 & 68 & 93 & 296 & 109 & 124 & 193 \\
\hline & Mulund & Through & 49 & 107 & 165 & 309 & 212 & 232 & 297 \\
\hline & Mulund & Left & 43 & 101 & 159 & 302 & 206 & 226 & 291 \\
\hline \multirow[t]{4}{*}{ Avg. delay (s) } & Thane & All & 9 & 10 & 11 & 11 & 11 & 11 & 11 \\
\hline & Airoli & All & 16 & 18 & 24 & 93 & 34 & 44 & 82 \\
\hline & Mumbai & All & 21 & 24 & 30 & 37 & 22 & 24 & 26 \\
\hline & Mulund & All & 12 & 18 & 26 & 95 & 37 & 39 & 64 \\
\hline \multirow[t]{4}{*}{ Avg. stop time (s) } & Thane & All & 7 & 8 & 8 & 8 & 8 & 8 & 8 \\
\hline & Airoli & All & 13 & 14 & 17 & 53 & 22 & 26 & 47 \\
\hline & Mumbai & All & 17 & 14 & 22 & 28 & 16 & 17 & 19 \\
\hline & Mulund & All & 9 & 12 & 18 & 62 & 25 & 27 & 42 \\
\hline \multirow[t]{4}{*}{ Stops/vehicle } & Thane & All & 0.25 & 0.29 & 0.32 & 0.33 & 0.33 & 0.34 & 0.32 \\
\hline & Airoli & All & 0.40 & 0.50 & 0.74 & 4.22 & 1.17 & 1.70 & 3.71 \\
\hline & Mumbai & All & 0.61 & 0.78 & 0.91 & 0.99 & 0.67 & 0.72 & 0.80 \\
\hline & Mulund & All & 0.32 & 0.53 & 0.82 & 3.86 & 1.23 & 1.33 & 2.51 \\
\hline
\end{tabular}

right and through movements from Airoli as well as left and through movements from Mulund showed significant increase in MOE parameter values beyond the traffic flow level IIIb. Hence, the proposed layout if implemented at the case study location would operate better than the existing condition up to traffic flow level IIIb for cycle length of 120 s. Similar observations can be made from Figs. 7 and 8. Here, the horizontal lines represent the average queue length (AQL) in Fig. 7 and average delay (AD) in Fig. 8 for the existing intersection operating at 200 s cycle length with the present level of traffic flow; whereas, the vertical bars represents $\mathrm{AQL}$ and $\mathrm{AD}$ at various traffic flow levels for the proposed layout operating at $120 \mathrm{~s}$ cycle length. At traffic flow level IIIc and IV, AD and AQL for the proposed layout operating at $120 \mathrm{~s}$ cycle length increases significantly and is comparable to the existing intersection at its present state. In fact, the expected AQL for through movements along the cross road connecting Airoli and Mulund, and the left-turning movement from Mulund would be more than the existing scenario. However, the AQL of right-turning movements from any direction for all flow levels considered (except from Mumbai for flow level IV) is better than the existing scenario. It is to be noted that the right-turning movements are critical for left-hand driving rules in India. Moreover, the $\mathrm{AD}$ for traffic movements from any direction at all flow levels considered 


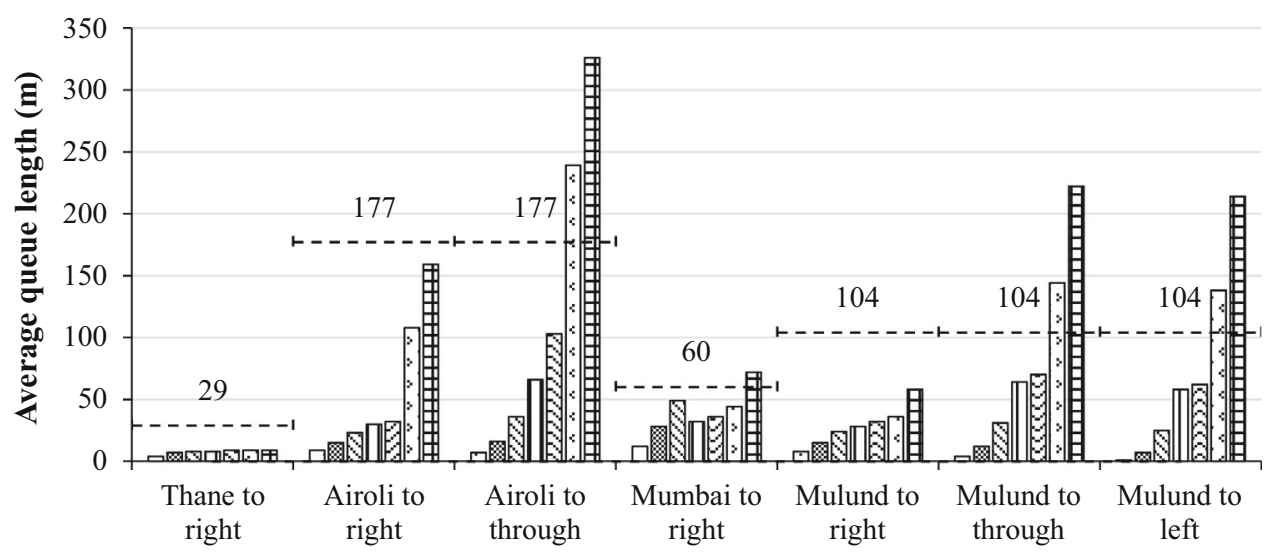

Direction of traffic

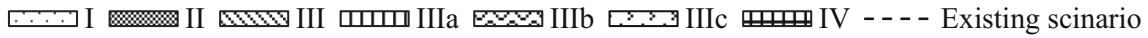

Fig. 7 Average queue length of the proposed layout at various flow levels and existing scenario

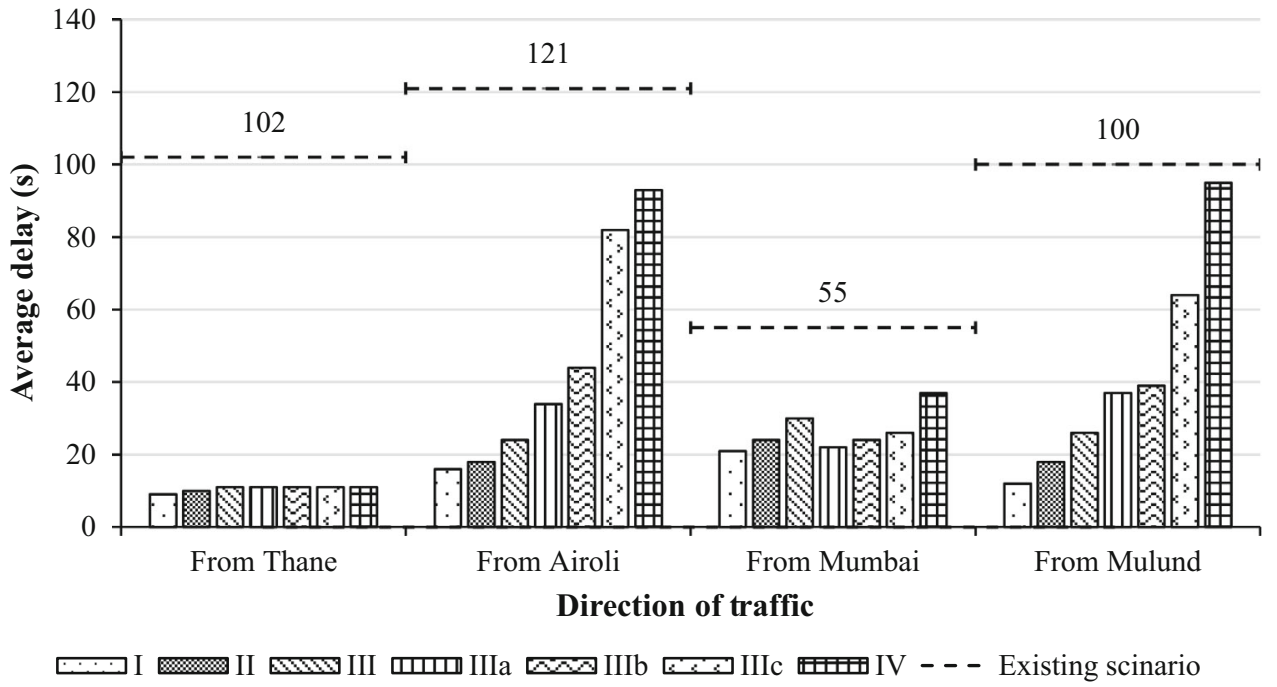

Fig. 8 Average delay of the proposed layout at various flow levels and existing scenario

is lower than the existing scenario. This indicates that the proposed layout if implemented at the case study location would serve well for considerable time in future.

\section{Discussion and conclusion}

A new intersection layout applicable at intersections under a flyover for Indian traffic conditions is proposed in this paper. The performance of the proposed new layout is evaluated for a case study location in Mumbai, India. Both, existing and proposed, intersection layouts for this location are modeled and simulated using microsimulation software, VISSIM, for the performance evaluation. Various MOEs such as average delay, queue length, number of stops per vehicle, average stopping time, etc., are compared in the evaluation process. It is observed from the simulation results that the proposed new layout is promising and operates efficiently compared to the existing layout. The proposed intersection layout demonstrated significant improvements in average queue length and average delay. It also helped in reducing the number of phases required to manage traffic in the present scenario and thus cut down the cycle length. Overall, if the proposed layout is adopted, the intersection level of service would improve considerably and the available intersection space could be segregated effectively to efficiently and safely manage the heterogeneous traffic.

The channelization islands and the raised traffic separators proposed in the layout could be a concern to the highway agencies maintaining the intersections. Traffic with weak lane discipline often damages the curb and thus 
may require frequent maintenance of the channelization islands and the raised traffic separators. Moreover, it would create enclosed sections that require additional care for effective rain water drainage and snow removal at locations subject to snowfall. In contrary, the channelization islands and the raised traffic separators are helpful in providing effective guidance to the driver population. It also enables to safely manage the simultaneous right-turning movement that is not common in India. Hence, the proposed layout would implicitly help in implementing safety enforcement, providing training and education to the driver population who do not display lane discipline.

Acknowledgments We acknowledge Indian Institute of Technology Bombay and Indian Institute of Technology Guwahati for providing us the required infrastructure and computation facility to carry out the research work.

Open Access This article is distributed under the terms of the Creative Commons Attribution 4.0 International License (http:// creativecommons.org/licenses/by/4.0/), which permits unrestricted use, distribution, and reproduction in any medium, provided you give appropriate credit to the original author(s) and the source, provide a link to the Creative Commons license, and indicate if changes were made.

\section{References}

1. AASHO (1965) A Policy on geometric design of rural highways. American Association of State Highway Officials, Washington

2. Bonilla C, Urbanik T (1987) Increased capacity of highways and arterials through the use of flyovers and grade separated rampsarterial flyovers. Research report 376-1, Texas Transportation Institute, Texas A\&M University, College Station, Jun 1987

3. Bonneson JA, Fontaine MD (2001) Evaluating intersection improvements: an engineering study guide. National cooperative highway research program report no. 457, National Academy Press

4. Day CM, Bullock DM, Li H, Remias SM, Hainen AM, Freije RS, Stevens AL, Sturdevant JR, Brennan TM (2014) Performance measures for traffic signal systems: an outcome-oriented approach. Purdue University, West Lafayette

5. Wang L, Zhang K, Mao B, Chen S (2009) Continuous simulation-based conflict-point detection model for heterogeneous mixed traffic flows in an urban intersection. Compendium of papers in 88th annual meeting of the transportation research board, National Academies, Washington, DC

6. Lu J, Pan F, Xiang Q (2008) "Level-of-safety service for safety performance evaluation of highway intersections. Transp Res Rec 2075:24-33

7. Abdel-Aty M, Wang X, Santos J (2009) Identifying intersectionrelated traffic crashes for accurate safety representation. J Inst Transp Eng 79(12):38-44

8. Stamatiadis N, Kirk A, Agarwal N, Jones C (2011) Improving intersection design practices. Report No. KTC-10-09/SPR-380-
09-1F, Kentucky Transportation Center, University of Kentucky, Lexington, KY

9. Dhatrak A, Edara P, Bared J (2010) Performance analysis of parallel flow intersection and displaced left-turn intersection designs. Transp Res Rec 2171:33-43

10. Jagannathan R, Bared J (2004) Design and operational performance of crossover displaced left-turn intersections. Transp Res Rec 1881:1-10

11. Kar PP, Maji A (2013) Ramp crossover interchange: developing the hybrid unconventional interchange. ITE J 83(5):28-35

12. Maji A, Mishra S, Jha M (2013) Diverging diamond interchange analysis: planning tool. J Transp Eng 139(12):1201-1210

13. Bared J, Edara P, Jagannathan R (2005) Design and operational performance of double crossover intersection and diverging diamond interchange. Transp Res Rec 1912:31-38

14. Autey J, Sayed T, Esawey M (2013) Operational performance comparison of four unconventional intersection designs using micro-simulation. J Adv Transp 47(5):536-552

15. Esawey ME, Sayed T (2007) Comparison of two unconventional intersection schemes: crossover displaced left-turn and upstream signalized crossover intersections. Transp Res Rec 2023:10-19

16. Reid J, Hummer J (2001) Travel time comparisons between seven unconventional arterial intersection designs. Transp Res Rec 1751:56-66

17. Vedagiri P, Daydar S (2012) Performance analysis of continuous flow intersection in mixed traffic condition. Int $\mathrm{J}$ Transp Urban Dev 2(1):20-25

18. Maji A, Bhattacharya P (2011) Methodology for innovative intersection design. Compendium of papers in 1st conference of transportation research group of India, Transportation Research Group of India, Bangalore

19. Arasan VT, Koshy R (2005) Methodology for modeling highly heterogeneous traffic flow. J Transp Eng 131(7):544-551

20. Koshy RZ, Arasan V (2005) Influence of bus stops on flow characteristics of mixed traffic. J Transp Eng 131(8):640-643

21. Mathew T, Radhakrishnan P (2010) Calibration of micro simulation models for no lane-based heterogeneous traffic at signalized intersections. J Urban Plan Dev 136(1):59-66

22. IRC: 73-1980 (1980) Geometric design standards for rural (nonurban) highways. The Indian Roads Congress, New Delhi

23. IRC: 86-1983 (1983) Geometric design standards for urban roads in plain. The Indian Roads Congress, New Delhi

24. Ministry of Road Transport \& Highways (MORTH) (2010) Guidelines for expressways. Indian Roads Congress, New Delhi

25. IRC: SP 41-1994 (1994) Guidelines for the design of at-grade intersections in rural \& urban area. The Indian Roads Congress, New Delhi

26. AASHTO (2011) A policy on geometric design of highways and streets. American Association of State Highway and Transportation Officials, Washington

27. Manjunatha P, Vortisch P, MathewT (2013) Methodology for the calibration of VISSIM in mixed traffic. Compendium of papers in 92nd annual meeting of the transportation research board, National Academies, Washington, DC

28. Siddharth SMP, Ramadurai G (2013) Calibration of VISSIM for Indian heterogeneous traffic conditions. Compendium of papers in 2nd conference of transportation research group of India, Transportation Research Group of India, Agra

29. Maurya A, Sharma S, Biswas S (2011) Modeling heterogeneous traffic using VISSIM. Compendium of papers in national conference on recent advances on civil engineering (RACE-2011), Varanasi 